\title{
Combined Sciatic, Femoral, and Obturator Nerve Blocks for Ankle Surgery in a Patient with Severe Pulmonary Hypertension-A Case Report
}

\author{
Ju Hyun Lee, Hyun Su Shin, Ki Yoon Kim, Ji Seon Jeong, Justin Sangwook Ko* \\ Department of Anesthesiology and Pain Medicine, Samsung Medical Center, School of Medicine, Sungkyunkwan University, \\ Seoul, Korea \\ Email: ^jsko@skku.edu
}

How to cite this paper: Lee, J.H., Shin, H.S., Kim, K.Y., Jeong, J.S. and Ko, J.S. (2017) Combined Sciatic, Femoral, and Obturator Nerve Blocks for Ankle Surgery in a Patient with Severe Pulmonary Hypertension-A Case Report. Open Journal of Anesthesiology, 7, 203-209.

https://doi.org/10.4236/ojanes.2017.78022

Received: July 11, 2017

Accepted: August 13, 2017

Published: August 16, 2017

Copyright (ㅇ 2017 by authors and Scientific Research Publishing Inc. This work is licensed under the Creative Commons Attribution International License (CC BY 4.0).

http://creativecommons.org/licenses/by/4.0/

\begin{abstract}
We report a patient with severe pulmonary arterial hypertension (PAH) undergoing tibio-talo-calcaneal fusion due to Charcot joint. Despite the advancement in the management of $\mathrm{PAH}$, the risks of anesthesia, surgery, and postoperative morbidity and mortality still remain high. A 46-year-old female was presented with severe $\mathrm{PAH}$ and end stage renal disease requiring hemodialysis three times a week. Ultrasound-guided sciatic, femoral, and obturator nerve blocks were performed with $0.5 \%$ levobupivacaine $15 \mathrm{ml}, 10 \mathrm{ml}$, and 5 $\mathrm{ml}$, respectively. All the blocks were successful, and the patient underwent uneventful anesthesia and surgery. In addition, the postoperative pain control lasted for $15 \mathrm{~h}$ and the patient was discharged on POD 5 without any complications. Therefore, ultrasound-guided sciatic, femoral, and obturator nerve blocks are valuable alternative to the general or neuraxial anesthesia in patients with severe pulmonary hypertension.
\end{abstract}

\section{Keywords}

Femoral Nerve Block, Obturator Nerve Block, Sciatic Nerve Block, Severe Pulmonary Hypertension, Ultrasound-Guided

\section{Introduction}

Pulmonary arterial hypertension (PAH) is a disease marked by progressive increase in pulmonary vascular resistance leading to right ventricular failure and death, and is defined as the mean pulmonary arterial pressure (mPAP) greater than $25 \mathrm{mmHg}$ at rest or $30 \mathrm{mmHg}$ during exercise confirmed by right heart ca- 
theterization. Among the etiologies of $\mathrm{PAH}$, connective tissue disease, congenital heart disease, and idiopathic PAH account for the majority [1]. The increased pressures in the pulmonary arteries render the right heart more difficult to properly pump blood, and in severe cases, PAH can lead to right heart failure. Symptoms associated with PAH include shortness of breath, chest pain, arrhythmias, fatigue, dizziness, etc. [1] [2] [3]. The incidence of pulmonary arterial hypertension is reported to be 1.9 patients per million people, annually, and the mortality rate is estimated as 7 per 100 people [4].

Along with the progress of medical treatment, many patients with PAH show improved symptoms and survival rates resulting in the increased chance for these patients to present for various types of surgery. However, despite the advanced surgical and anesthetic management, the risks of perioperative morbidity and mortality still remain substantially high. While general and regional anesthesia carries potential risks, optimal selection and careful anesthetic management are warranted for these patients.

Herein, we report a patient with severe PAH who underwent a successful regional anesthesia with ultrasound-guided sciatic, femoral, and obturator nerve blocks for tibio-talo-calcaneal fusion due to Charcot joint.

\section{Case Report}

A 46-year-old woman $(154.8 \mathrm{~cm}, 48 \mathrm{~kg})$ was admitted for tibio-talo-calcaneal fusion due to Charcot joint of her left ankle. The patient was referred to the tertiary medical care because of high risks of the anesthesia and surgery. The patient was diagnosed with $\mathrm{PAH}$ four years ago and has been receiving medical treatments including calcium channel blocker, $\beta$-blocker, antiplatelet drug, oral hypoglycemic agent and insulin therapy. Her present illness showed no associated symptoms such as exertional dyspnea, peripheral edema or chest pain. She had end stage renal disease (ESRD) secondary to diabetes mellitus and has been undergoing hemodialysis via arteriovenous graft 3 days a week since 2008. She was a hepatitis $C$ virus carrier without hepatic manifestations. There was no family history of PAH for this patient.

Preoperative echocardiogram (ECG) showed normal sinus rhythm and right axis deviation. Transthoracic Doppler echocardiography (TTE) showed right ventricular systolic pressure (RVSP) value of $79.2 \mathrm{mmHg}$ estimated by adding the peak systolic regurgitant flow velocity of tricuspid valve to the assumed right atrial pressure of $10 \mathrm{mmHg}$ [5] [6]. It also showed dilated pulmonary artery and enlarged right ventricular cavity size. However, both the right and left ventricular systolic functions were normal without regional wall motion abnormality and the left ventricular ejection fraction was 59\%. To evaluate the PAH more accurately, the right heart catheterization was performed. The result showed the pulmonary arterial pressure of 85/50/23 $\mathrm{mmHg}$ (systolic/mean/diastolic) and negative pulmonary vasodilator test using nitric oxide $(\mathrm{NO})$ and oxygen $\left(\mathrm{O}_{2}\right)$ (Table 1). Pulmonary function test (PFT) showed severe restrictive pattern with 
Table 1. Patient characteristics and hemodynamic parameters.

\begin{tabular}{|c|c|c|c|c|}
\hline \multicolumn{5}{|c|}{$\mathrm{F} / 46,(154.9 \mathrm{~cm}, 48 \mathrm{~kg})$} \\
\hline \multicolumn{5}{|c|}{ TTE } \\
\hline \multicolumn{4}{|c|}{ Right ventricular systolic pressure, $\mathrm{mmHg}$} & 79.2 \\
\hline \multicolumn{4}{|c|}{ Left ventricular ejection fraction, $\%$} & $59 \%$ \\
\hline \multicolumn{5}{|c|}{ Cardiac catheterization } \\
\hline \multicolumn{4}{|c|}{ Pulmonary artery pressures, $\mathrm{mmHg}$ (systolic/mean/diastolic) } & $85 / 50 / 23$ \\
\hline \multicolumn{5}{|c|}{ Hemodynamic parameters } \\
\hline & Baseline & $1 \mathrm{~h}$ after surgery & End of surgery & POD 1 \\
\hline $\begin{array}{l}\text { Blood pressures, mmHg } \\
\text { (systolic/mean/diastolic) }\end{array}$ & $142 / 82 / 50$ & $155 / 92 / 55$ & $170 / 102 / 60$ & $123 / 75 / 58$ \\
\hline Heart rates, beat $/ \mathrm{min}$ & 53 & 60 & 65 & 77 \\
\hline
\end{tabular}

Abbreviation: TTE, transthoracic Doppler echocardiography.

decreased forced expiratory volume in 1 second (43\%), forced vital capacity (47\%) and diffusing capacity of the lungs for carbon monoxide (44\%). Arterial blood gas analysis at room air showed $\mathrm{pH} 7.347, \mathrm{PaCO}_{2} 39.8 \mathrm{mmHg}$, and $\mathrm{PaO}_{2}$ $52.8 \mathrm{mmHg}$. Her chest radiography and chest computerized tomography (CT) revealed no signs of pulmonary thromboembolism. After extensive work ups, the patient was finally diagnosed with severe idiopathic PAH in the absence of connective tissue disease, congenital heart and lung diseases.

For the patient's anesthetic management, the regional anesthesia comprising the sciatic, femoral, and obturator nerve blocks was planned for her ankle surgery. The obturator nerve block was also selected because of intended tourniquet application at the distal thigh. The ultrasound-guided nerve blocks were performed in the block room. The patient's basic monitoring included electrocardiogram, pulse oximetry and noninvasive blood pressure. After administering 1 $\mathrm{mg}$ of midazolam to minimize patient's discomfort, an invasive blood pressure monitoring was achieved with 22 gauge angiocatheter at right radial artery after local injection. The oxygen was delivered through a facial mask at $4 \mathrm{~L} / \mathrm{min}$.

The patient was placed in the right lateral decubitus position, and the ultrasound-guided sciatic nerve block was performed at the proximal one third thigh level. After sterile skin preparation with a solution of chlorhexidine $2 \%$ in isopropyl alcohol $70 \%$ and skin infiltration with $2 \mathrm{ml}$ of $1 \%$ lidocaine, a sterile 100 mm 22 G insulated nerve stimulating needle (PAJUNK ${ }^{\circledR}$, Geisingen, Germany) was inserted in-plane technique using linear transducer $(8-12 \mathrm{MHz})$ until the needle tip was adjacent to the sciatic nerve, and appropriate needle position was confirmed at a threshold current less than $0.5 \mathrm{~mA}$. After negative aspiration test for blood, $15 \mathrm{ml}$ of $0.5 \%$ levobupivacaine was slowly injected while observing perineural spread of local anesthetics (Figure 1(A)). Next, the patient was placed in supine position with the leg slightly abducted and externally rotated. After the sterile skin preparation and local infiltration, the femoral nerve block was per- 

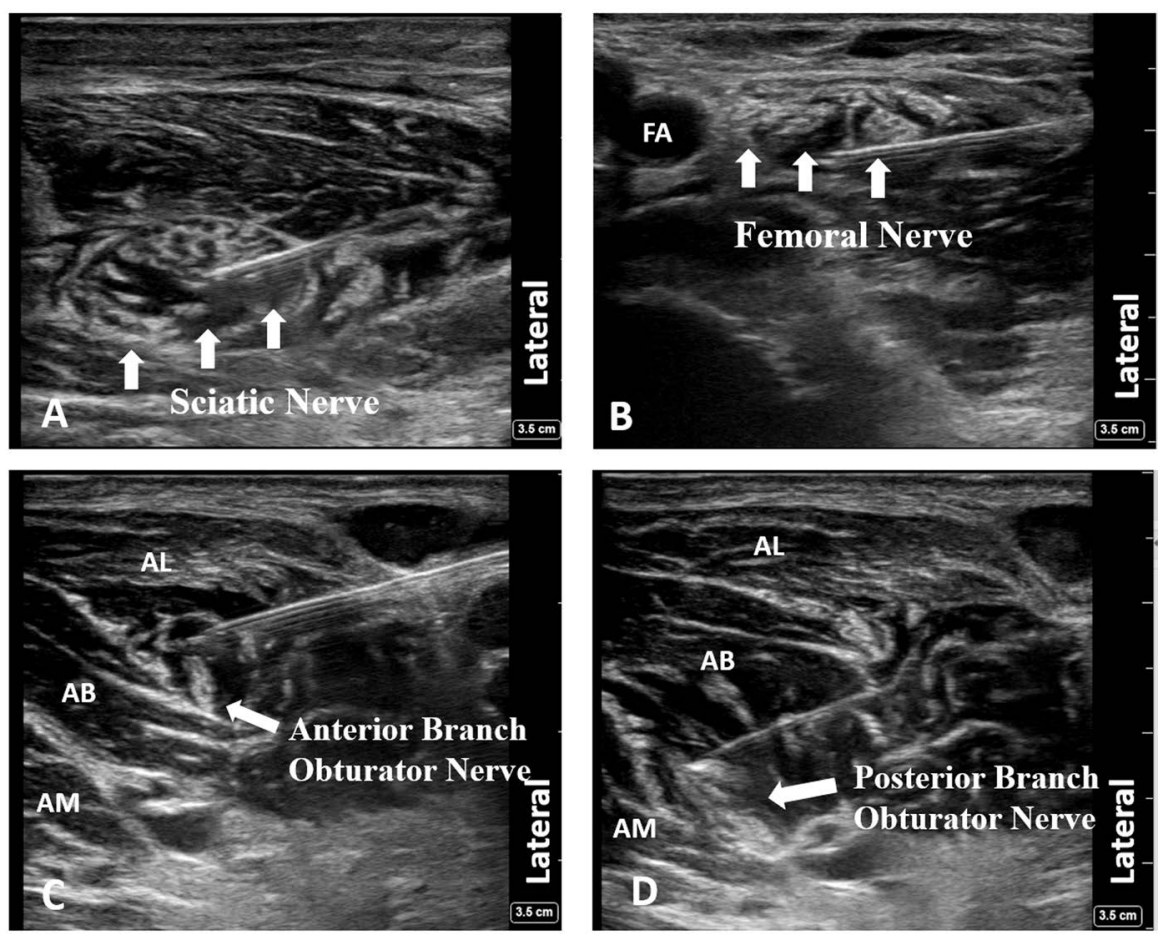

Abbreviations: FA, femoral artery; $\mathrm{AL}$, adductor longus muscle; $\mathrm{AB}$, adductor brevis muscle; $\mathrm{AM}$, adductor magnus muscle.

Figure 1. (A) Sciatic nerve block, (B) Femoral nerve block, (C) Anterior branch of the obturator nerve block, (D) Posterior branch of the obturator nerve block.

formed at the inguinal crease level by advancing $100 \mathrm{~mm} 22 \mathrm{G}$ insulated nerve stimulating needle in-plane from the lateral to medial direction toward the femoral nerve. The fascia iliaca was punctured and the needle tip was placed adjacent to the femoral nerve. The proper needle tip position was confirmed by the motor response of quadriceps muscles elicited by a threshold current less than $0.5 \mathrm{~mA}$. Once aspiration was negative for blood, the $10 \mathrm{ml}$ of $0.5 \%$ levobupivacaine was perineurally injected (Figure 1 (B)). After femoral nerve block, the transducer was moved medially along the inguinal crease and identified the adductor muscles and both the anterior and posterior branches of the obturator nerve. First, the needle was advanced toward the anterior branch and $2.5 \mathrm{ml}$ of $0.5 \%$ levobupivacaine was injected (Figure $1(\mathrm{C})$ ) followed by $2.5 \mathrm{ml}$ of $0.5 \%$ levobupivacaine around posterior branch (Figure 1(D)). All the blocks were successful and the surgical anesthesia was achieved after 40 minutes.

The patient was then transferred to the operating room. Her initial blood pressure was 142/82/50 $\mathrm{mmHg}$ (systolic/mean/diastolic) and heart rate was 53 per minute. The tourniquet was placed on her left distal thigh and the pressure was maintained at $300 \mathrm{mmHg}$. Midazolam $1 \mathrm{mg}$ was injected followed by continuous infusion of remifentanil (range $0.5 \sim 0.7 \mathrm{mcg} / \mathrm{kg} / \mathrm{min}$ ). Her vital signs were stable throughout the operation. The surgery lasted for 170 minutes and the patient was transferred to the intensive care unit (ICU) for the close observation. The patient's vital signs were stable in the ICU, and on POD 1, she was 
transferred to the general ward. The hemodynamic parameters are shown in Table 1 . The nerve blocks provided an adequate postoperative pain control for 15 hours. On postoperative day 5 , the patient was discharged without complications.

Two months later, the patient was re-admitted for the hardware removal and incision and drainage of her previously operated left ankle due to infection. Again, the sciatic, femoral, and obturator nerve blocks were performed with $0.5 \%$ levobupivacaine $7 \mathrm{ml}, 13 \mathrm{ml}$, and $5 \mathrm{ml}$, respectively. The patient underwent uneventful surgery $(120 \mathrm{~min})$ and postoperative recovery, and she was discharged on POD 20 after the infection control. The patient was followed up for 5 months after the surgery and showed no evidence of complications.

\section{Discussion}

The patients with PAP have high risks of cardiopulmonary complications after various noncardiac surgeries and the echocardiographic pulmonary arterial systolic pressure over $70 \mathrm{mmHg}$ indicate significantly increased chance for postoperative complications including right ventricular failure, persistent postoperative hypoxia, coronary ischemia, and higher in-hospital mortality [7] [8]. In our patient, the pulmonary arterial systolic pressure was above $80 \mathrm{~mm} \mathrm{Hg}$, highly suggestive of increased risks of cardiopulmonary adverse events. In addition, various harmful conditions including hypoxia, hypercapnia, acidosis, pain and other surgical stresses during anesthesia and surgery could further exacerbate already increased pulmonary arterial pressure and lead to cardiovascular collapse.

The central neuraxial anesthesia is the most commonly performed method of anesthesia in lower extremity surgeries. However, systemic hypotension associated with spinal anesthesia can induce abrupt decrease in coronary perfusion of right ventricle, eventually leading to right ventricular failure in vulnerable patients. Therefore, a single-shot intrathecal anesthetic technique is generally avoided in hemodynamically compromised patients. Instead, epidural anesthesia or combined spinal-epidural anesthesia with low dose local anesthetics might be favored over spinal anesthesia in high risk patients [9]. However, regardless of the types of neuraxial anesthesia, there is still the risk of systemic hypotension caused by sympathetic blockade despite appropriate fluid administration and vasopressor use. In addition, the general anesthesia might not also be suitable for high risk patients because hemodynamic fluctuations can also occur in various time points including immediately after tracheal intubation, surgical incision and during the emergence [10].

Recently, the ultrasound-guided peripheral nerve blocks have gained great interest and might be considered as a valuable anesthetic option in patients with severe cardiovascular diseases. For example, Tantry et al. [11] reported two successful anesthetic cases managed with combined femoral and sciatic nerve blocks for a patient with severe rheumatic valvular heart disease and pulmonary hyper- 
tension undergoing emergent thrombo-embolectomy. Similarly, in our patient, the obturator nerve block was added to sciatic and femoral nerve blocks to relieve tourniquet pain in addition to surgical anesthesia. Agreeably, McNamee et al. [12] demonstrated that the obturator nerve block resulted in improvement of postoperative analgesic effects and reduced requirement of opioid analgesics when it was added to combined femoral and sciatic nerve blocks.

\section{Conclusion}

The peripheral nerve blocks comprising sciatic, femoral, and obturator nerve blocks might be considered as the alternative anesthetic choice to general or neuraxial anesthesia in patients with severe pulmonary hypertension undergoing lower extremity surgeries.

\section{References}

[1] Chung, W.J., Park, Y.B., Jeon, C.H., Jung, J.W., Ko, K.P., Choi, S.J., Seo, H.S., Lee, J.S. and Jung, H.O. (2015) Baseline Characteristics of the Korean Registry of Pulmonary Arterial Hypertension. Journal of Korean Medical Science, 30, 1429-1438. https://doi.org/10.3346/jkms.2015.30.10.1429

[2] Gaine, S.P. and Rubin, L.J. (1998) Primary Pulmonary Hypertension. The Lancet, 352, 719-725.

[3] Rubin, L.J. (1997) Primary Pulmonary Hypertension. The New England Journal of Medicine, 336, 111-117. https://doi.org/10.1056/NEJM199701093360207

[4] Barst, R.J., McGoon, M., Torbicki, A., Sitbon, O., Krowka, M.J., Olschewski, H. and Gaine, S. (2004) Diagnosis and Differential Assessment of Pulmonary Arterial Hypertension. Journal of the American College of Cardiology, 43, 40-47.

[5] Currie, P.J., Seward, J.B., Chan, K.L., Fyfe, D.A., Hagler, D.J., Mair, D.D., Reeder, G.S., Nishimura, R.A. and Tajik, A.J. (1985) Continuous Wave Doppler Determination of Right Ventricular Pressure: A Simultaneous Doppler-Catheterization Study in 127 Patients. Journal of the American College of Cardiology, 6, 750-756.

[6] Ommen, S.R., Nishimura, R.A., Hurrell, D.G. and Klarich, K.W. (2000) Assessment of Right Atrial Pressure with 2-Dimensional and Doppler Echocardiography: A Simultaneous Catheterization and Echocardiographic Study. Mayo Clinic Proceedings, 75, 24-29. https://doi.org/10.4065/75.1.24

[7] Lai, H.C., Lai, H.C., Wang, K.Y., Lee, W.L., Ting, C.T. and Liu, T.J. (2007) Severe Pulmonary Hypertension Complicates Postoperative Outcome of Non-Cardiac Surgery. British Journal of Anaesthesia, 99, 184-190.

https://doi.org/10.1093/bja/aem126

[8] Ramakrishna, G., Sprung, J., Ravi, B.S., Chandrasekaran, K. and McGoon, M.D. (2005) Impact of Pulmonary Hypertension on the Outcomes of Noncardiac Surgery: Predictors of Perioperative Morbidity and Mortality. Journal of the American College of Cardiology, 45, 1691-1699.

[9] Bonnin, M., Mercier, F.J., Sitbon, O., Roger-Christoph, S., Jais, X., Humbert, M., Audibert, F., Frydman, R., Simonneau, G. and Benhamou, D. (2005) Severe Pulmonary Hypertension during Pregnancy: Mode of Delivery and Anesthetic Management of 15 Consecutive Cases. Anesthesiology, 102, 1133-1137. https://doi.org/10.1097/00000542-200506000-00012

[10] Prys-Roberts, C., Greene, L.T., Meloche, R. and Foex, P. (1971) Studies of Anaes- 
thesia in Relation to Hypertension. II. Haemodynamic Consequences of Induction and Endotracheal Intubation. British Journal of Anaesthesia, 43, 531-547. https://doi.org/10.1093/bja/43.6.531

[11] Tantry, T.P., Kadam, D., Shetty, P. and Bhandary, S. (2010) Combined Femoral and Sciatic Nerve Blocks for Lower Limb Anaesthesia in Anticoagulated Patients with Severe Cardiac Valvular Lesions. Indian Journal of Anaesthesia, 54, 235-238. https://doi.org/10.4103/0019-5049.65372

[12] McNamee, D.A., Parks, L. and Milligan, K.R. (2002) Post-Operative Analgesia Following Total Knee Replacement: An Evaluation of the Addition of an Obturator Nerve Block to Combined Femoral and Sciatic Nerve Block. Acta Anaesthesiologica Scandinavica, 46, 95-99. https://doi.org/10.1034/j.1399-6576.2002.460117.x

Submit or recommend next manuscript to SCIRP and we will provide best service for you:

Accepting pre-submission inquiries through Email, Facebook, LinkedIn, Twitter, etc. A wide selection of journals (inclusive of 9 subjects, more than 200 journals) Providing 24-hour high-quality service User-friendly online submission system Fair and swift peer-review system Efficient typesetting and proofreading procedure Display of the result of downloads and visits, as well as the number of cited articles Maximum dissemination of your research work

Submit your manuscript at: http://papersubmission.scirp.org/ Or contact ojanes@scirp.org 